\title{
Juan Palomeque y otros «sinónomos voluntarios» entre Cervantes y Lope de Vega
}

\author{
Abraham MadroñaL
}

\begin{abstract}
Resumen
El trabajo pretende demostrar que algunos nombres de la primera parte del Quijote tienen un significado malicioso para algunos intelectuales de la época, como Lope de Vega. Serían los "sinónomos voluntarios" que reprochó Avellaneda a Cervantes. Uno de ellos es precisamente Juan Palomeque, que se puede interpretar como una burla de esa ilustre familia de mozárabes toledanos.
\end{abstract}

Palabras Clave: Juan Palomeque; Lope de Vega; mozarabs; sinónomos voluntarios; Toledo.

Title: Juan Palomeque and Other «Sinónomos Voluntarios» between Cervantes and Lope de Vega

\begin{abstract}
This article shows that some names of the first part of Don Quixote have a malicious meaning for some intellectuals of the time, as Lope de Vega. These names would be the "sinónomos voluntarios" that reproaches Avellaneda to Cervantes. One of them is "Juan Palomeque", which can be interpreted as a mockery of that illustrious family of Toledo mozarabs.
\end{abstract}

Key Words: Juan Palomeque; Lope de Vega; mozarabs; volunteers synonyms; Toledo.

Una de las más agrias censuras que Avellaneda dirige a Cervantes es el haber empleado en la primera parte del Quijote «sinónomos voluntarios»

*Universidad de Ginebra. abraham.madronal@cchs.csic.es 
y haber ofendido en parte por ellos a Lope y a él o al dramaturgo y a mil más, según la edición que sigamos ${ }^{1}$. Mucho se ha escrito sobre el sentido de esas palabras y en particular con la intención de descubrir cuáles son tales sinónimos, porque detrás de los mismos está la siempre enigmática identidad del falsario Avellaneda.

Para algunos los tales sinónimos son aquellas palabras que significan lo mismo que otras y que Cervantes parece acumular a lo largo de su libro [Rosenblat, 2014, p. 118]; pero para otros tal rasgo estilístico no parecía lo suficientemente grave como para que Avellaneda se quejara de ello y prefieren interpretar el pasaje como aquellos nombres o perífrasis alusivas que voluntariamente encubrían otros nombres o servían para hacer burla descarada de personas concretas o de colectivos. Rodríguez Marín sugería que se trataba más bien de «apodos, alias, motes» [1948, pp. 143-144] y estudiosos más recientes han apuntado en la dirección concreta de algunos intelectuales toledanos amigos de Lope [Pérez López, 2002]. Aunque ambas opiniones son posibles, el que los «sinónomos» sean o no alusiones de Cervantes a nombres reales no impide que en las páginas del Quijote existieran referencias a personas, familias o lugares que pudieron entenderse como una burla.

Toda esta polémica hay que situarla en los momentos próximos a la aparición del primer Quijote, es decir, cuando Lope se ha instalado en Toledo a consecuencia del destierro (1604), y ha constituido en torno a él un grupo de intelectuales que lo reconocen como maestro, de la misma manera que el Fénix reconoce a la ciudad como patria a la que hay que defender y promocionar. Cuestiones espinosas como la disputa de la sede primada de la Iglesia (en pugna, por ejemplo, con Santiago de Compostela en ese momento) o la ubicación de la corte (que ya se sabía que dejaba su emplazamiento vallisoletano para quizá volver a su genuina ubicación toledana) suscitaban la cerrada defensa de una ciudad que se quería como sede de la monarquía goda y campeona del catolicismo, a pesar de los muchos años de dominio árabe. $\mathrm{Y}$ en esa labor de recuperación y embellecimiento se alistaba Lope junto a un grupo importante de artistas e intelectuales.

\section{EL ORIGEN: CIDE HAMETE BENENEGELI}

De repente, un escritor como Cervantes publicaba un libro en el que se podían adivinar algunas ofensas desde luego a Lope y, quizá también, a algunas realidades de su entorno toledano, en parte por medio de esos sinónomos voluntarios. Creo que en esa situación se encuentran algunos nombres de persona de la obra, como el del autor árabe de la misma: cide Hamete Benengeli. Es

1. «He tomado por medio entremesar la presente comedia con las simplicidades de Sancho Panza, huyendo de ofender a nadie ni de hacer ostentación de sinónomos voluntarios» (Fernández de Avellaneda, 2014: 44). Por su parte, véase Suárez Figaredo [2008]. 
sabido que la ciudad de Toledo se quiere presentar por parte de los historiadores locales de la época clásica como un lugar en el que desde su instauración había predominado el cristianismo, incluso durante la dominación visigoda o árabe. La cosa resultaba más fácil en el primero de los casos, por cuanto los visigodos habían acabado abrazando la religión de Cristo, y mucho más difícil en el segundo. Los toledanos habían querido borrar cualquier pasado musulmán en la ciudad, incluso los propios letreros arábigos [Martínez Gil, 2006] y proclamaban con orgullo el rito mozárabe, como heredero de los visigodos en los tiempos difíciles de la dominación musulmana. Y de repente, la historia del hidalgo manchego se encuentra en el Alcaná de Toledo escrita en árabe por un historiador de esa procedencia y es traducida por un morisco no en cualquier sitio, sino paseando «por el claustro» de la catedral. Y para colmo de males, dicho historiador tenía nombre chusco y ofensivo.

Porque Cide Hamete Benegeli, o Cide Hamete Berenjena, como quiere Sancho en los primeros capítulos de la Segunda parte del Quijote (1615), es un claro mote contra los toledanos de la capital, a los que se llamaba «berenjeneros» por su aprecio de esta hortaliza, según nos dice Luis Hurtado de Toledo en sus Relaciones topográficas, cuando le toca hablar de la ciudad:

abundan tanbien esta huerta de la fruta que de los sotos emos contado y de las venenosas verengenas, que a los toledanos dan adverso renonbre, digo adverso porque llamarlos verengeneros no lo causa esta fruta sino sachique que la hazen en la caza a quien los enoja y como la verengena es ynchada y cardena o cerulea en su color tal es la fruta questos toledanos criauan con los puños en los rostros de sus enemigos, quando no avia tanta copia de armas ofensivas para conbatir desde lejos [Hurtado de Toledo, Memorial de ...Toledo, p. 502].

Pero es evidente que el nombre esconde una significación suplementaria mucho más hiriente: con él se les acusa de ser cristianos nuevos, como escribe Sebastián de Horozco en el Libro de los proverbios glosados:

Toledano, aho berengena ya no las como que soy de Llerena.

Este proverbio se dize porque a los toledanos llaman berengeneros diziendo que en Toledo ay muchas berengenas. $\mathrm{Y}$ así comen muchas de ellas. $\mathrm{Y}$ el, «aho,» quieren dezir que es porque en Toledo gorjeando a los niños y mostrándoles a comer les dan berengenas diziéndoles, «Aho,» con la berengena, mas el de Toledo responde maliçiosamente diziendo, "Ya no las como que soy de Llerena.» Y esto es porque en Llerena y aún en otros muchos lugares de estos reynos ay y se crían y se comen muchas más berengenas que en Toledo. Y así dezir, «No la como que soy de Llerena,» es querer dezir que los de Llerena son los que las comen y por quien mejor se podría dezir el de Llerena, «Aho, berengena,» porque los de Llerena comen muchas más berengenas que los toledanos. Y aún lo mismo se podría dezir a los de Sevilla donde ay más y se comen más berengenas que en diez Toledos y mayores y de peor sabor porque en Toledo son pocas las que ay y éssas de muy buenas simientes medianas y de buen mantenimiento 
de las quales no solamente los confesos por quien por ventura se dixo el refrán mas aún los xpianos viejos, hijosdalgo y caballeros, clérigos y legos y de todas suertes comen de diversas maneras. Así que la berengena de Toledo no se tiene por manjar de judíos ni por razón de ellas pueden ser motejados de confessos los toledanos como los neçios lo entienden. Y más por lo que verdaderamente se pudo dezir y se dixo este refrán, «Toledano, aho berengena,» es prosupuesto que las ojeras y cardenales en los ojos y cara se llaman berengenas. «Toledano, aho berengena,» quiere dezir que el toledano desde niño sabe hazer berengenas a otros en los ojos y hoçicos y él no las come ni las sabe reçebir [Horozco, Proverbios glosados, p. 482].

No digo que fuera intención de Cervantes, pero sí es muy probable que un Lope que se sentía agredido directamente (en particular, las críticas a su teatro) consiguiera convencer a su grupo de intelectuales toledanos de que a ofensa no iba solamente contra él, sino contra la ciudad entera y su deseo de ennoblecimiento. Puede que en su comedia El Hamete de Toledo (a1608), Lope ajustara las cuentas a este Hamete Benegeli, pues -como es sabido- la obra termina con la tortura y muerte del protagonista musulmán [Madroñal, 2013].

\section{EL CURIOSO CASO DE JUAN HALDUDO}

De la misma manera creo que el nombre de Juan Haldudo, el rico, vecino de Quintanar y maltratador del joven Andrés, puede ser también sinónimo voluntario contra el mismo Lope y su obra. Porque el caso de este chico, azotado por su amo $(I, 4)$ es muy significativo por la relación que se puede encontrar con el llamado niño inocente de La Guardia (Toledo), objeto de una comedia homónima del Fénix. Reparemos en que don Quijote emprende esta aventura nada más haber sido armado caballero en la venta y que se encuentra en un bosque:

atada una yegua a una encina, y atado en otra a un muchacho desnudo de medio cuerpo arriba, hasta de edad de quince años, que era el que las voces daba, y no sin causa, porque le estaba dando con una pretina muchos azotes un labrador de buen talle, y cada azote le acompañaba con una reprehensión y consejo.

El muchacho replica:

No lo haré otra vez, señor mío; por la pasión de Dios, que no lo haré otra vez, y yo prometo de tener de aquí adelante más cuidado con el hato.

Cuando don Quijote le propone al amo Haldudo que le pague lo que le debe al muchacho y el labrador responde que no tiene dineros, pero que se vaya con él a su casa y le pagará, replica el muchacho:

— ¿Irme yo con él? -dijo el muchacho-. Mas ¡mal año! No, señor, ni por pienso, porque en viéndose solo me desuelle como a un San Bartolomé. 
Porque, informa al caballero, su amo es Juan Haldudo, el rico, vecino de Quintanar. A lo que contesta el hidalgo:

- Importa poco eso -respondió don Quijote-, que Haldudos puede haber caballeros; cuanto más, que cada uno es hijo de sus obras [Cervantes, Don Quijote, I, 2004, pp. 248-251].

Es decir, que «haldudo» o «faldudo» se opone en parte a «caballero»y es un término que aparece connotado negativamente. Para más inri, en el Quijote Ginés se apellida Pasamonte en el Quijote, que es el mismo apellido del niño de La Guardia, Juan o Cristóbal de Pasamonte. Quien le azota amarrado a un árbol (como a Cristo y al niño de La Guardia) es Juan Haldudo, el Rico, vecino de Quintanar. Haldudo significa el de las faldas largas, quizá como las que llevaban los sayones o judíos que martirizaron a Cristo, según el imaginario de la época; era rico como ellos y, además, vecino de Quintanar, como el personaje así llamado de El niño inocente de La Guardia que contribuye a azotar al pequeño protagonista de la obra. Pudo recordar a esa comedia de Lope, donde también se intenta identificar al niño asesinado con Jesucristo (primero se llama Juan y luego Cristóbal) y a su madre, Juana la Guindera, ciega a consecuencia de llorar por el rapto, con la Virgen y a los que lo asesinan, con los que tuvieron que ver en la pasión de Cristo: así Pilatos sería Hernando de Ribera, contador del prior de la orden de San Juan; Judas, Benito García de las Mesuras, que engaña al niño para raptarlo; Anás, el dicho judío de nombre Quintanar, que a veces se asemeja con Herodes, etc. Cervantes se atrevía a replicar a Lope, cuando este se había atrevido a criticar a Cervantes, contraponiendo al protagonista de El niño inocente (escrita antes de 1603, acaso poco antes) con el muchacho que se arroja desde la torre en Numancia:

Este sí que te honra más que el muchacho de Numancia, que si se echó con las llaves de aquella torre tan alta, este en la llave del cielo sube al cielo a ser estampa [Lope, El niño inocente de La Guardia, 2009, p. 1618].

Y en definitiva, la contraposición se daba entre Toledo y Numancia, lo que equivale a decir que se oponían una ciudad meridional frente a otra septentrional, acaso como capital de la España imperial:

Al fin, Toledo insigne, ínclita, fuerte,

Toledo la imperial, la ciudad noble, la cabeza de España, aquella antigua famosa corte de los reyes godos; ... aquella que en lealtad venció a Numancia [Lope, Relación de las fiestas, 1605, ff. 20-21]. 
La referencia a los azotes dados a Cristo, también atado a una columna y desnudo; la alusión a la pasión de Dios, el nombre de Quintanar, etc. nos permiten pensar en la analogía con el que la ciudad de Toledo estaba intentado santificar desde 1597 [Madroñal, en prensa a]. Porque, en efecto, fracasado el asunto de san Tirso, a Higuera se le ocurre un nuevo santo toledano y vuelve los ojos a un proceso de la Inquisición a finales de 1492, en que se ajustició a unos judíos por haber matado a un niño, al que hicieron padecer los mismos suplicios que a Cristo: el niño inocente de La Guardia. El caso es que el ayuntamiento toledano vuelve a encargar a Lope una comedia sobre este asunto.

Nombres todos, a mi entender, motivados y que pudieron interpretarse en clave burlesca e incluso hiriente por parte de Lope, que - no se olvide- vivía en Toledo desde 1604 y era considerado «poeta toledano», como se ha dicho.

\section{OTROS CASOS Y SU RELACIÓN CON LOPE Y SU CÍRCULO}

No son las únicas alusiones ofensivas o que se podían interpretar como tales hacia el teatro de Lope, según los nombres o sinónimos voluntarios que podían encontrarse en la historia de don Quijote: en otro lugar hemos sugerido la misma crítica que se puede apreciar en la referencia a Juan de Urbina y Diego García de Paredes, protagonistas de otra comedia del mismo Fénix de 1600 [Madroñal, 2010]. Igualmente, el nombre de Cardenio, el Roto, en el Quijote se parece mucho a Cardenio, el Rústico, personaje de La Arcadia (1598) de Lope, una obra -como se sabe- que Lope está escribiendo en las riberas del Tajo y en la que alud con claridad a los ingenios toledanos, uno de los cuales al menos, el contador Gaspar de Barrionuevo, dedica un poema laudatorio al libro y, según nuestra opinión, aparece en él con la máscara arcádica de Gaseno.

El nombre de Cardenio, incluso su apelativo y la manera de comportarse en la obra de Lope (se describe como ingenuo) nos permiten también pensar que a la fuerza el Fénix tuvo que considerarlo como sinónomo voluntario y como una burla también. Por otra parte, la trama en que Cardenio aparece en el Quijote no puede ser más cercana a una comedia de enredo: Cardenio, enamorado de Luscinda, es amigo de don Fernando, que está enamorado de Dorotea; cuando don Fernando abandone a esta, la joven se disfraza de hombre para reencontrarse con su amado. Don Fernando le quita la novia a Cardenio y se desposa con ella, mientras él está escondido detrás de una cortina. Todo muy teatral, como teatral es el final de la aventura, cuando las dos parejas vuelven con quien naturalmente tenían que quedarse: Cardenio con Luscinda y don Fernando con Dorotea. Enredos y final feliz, propios de una comedia lopesca, como las que tantas veces había estrenado el Fénix. Solo que comedia en prosa, como denunciaba Avellaneda que eran las más de las novelas de Cervantes. 


\section{UN PERSONAJE SINGULAR: JUAN PALOMEQUE, EL ZURDO}

Pero ahora me quiero centrar en el nombre de un ventero, sobre el cual se pueden añadir algunas cosas. En efecto, Juan Palomeque (el Zurdo, para más señas) aparece en la primera parte del Quijote y su nombre puede ser una clara ofensa a los mozárabes toledanos de este apellido, y a los mozárabes en general, muy alabados por el propio Lope y por otros amigos suyos como el padre jesuita Jerónimo Román de la Higuera, el famoso autor de los falsos cronicones (muerto en 1611), sobre el cual se ha escrito bastante [Martínez de la Escalera, 1991a; Caro Baroja, 1996; García Arenal y Rodríguez Mediano, 2009], pero no se ha apurado, creo, la importante relación que tiene con los dos protagonistas de estas páginas: Lope y Cervantes [Madroñal, en prensa b].

Prácticamente toda su obra quedó manuscrita en diferentes bibliotecas. Y en uno de sus muchos manuscritos inéditos, el titulado Familias de Toledo, glosa los apellidos más importantes de la ciudad y va señalando su descendencia. El caso es que sobre la familia que nos ocupa escribe nuestro jesuita:

Casa de los muzárabes Palomeques.

Uno de los ilustres, antiguos y nombrados linajes de los muzárabes de Toledo es el de los Palomeques; dicen que son descendientes de la ilustre casa de Matanza, la cual celebra por tal el arzobispo don Rodrigo, lib. 3 de su Historia, cap. 26 y desta casa fue el caballero que entró en la estacada en defensa del misal y oficio gótico, contra el castellano que defendía se había de quitar por el romano. Al fin, venció el de la Matanza, quiriendo Dios dar esta victoria en testimonio que no quería se quitase aquel santísimo oficio que con tanto celo compusieron los prelados góticos y reformaron y acrescentaron S. Leandro y S. Isidoro, S. Illefonso y S. Julián, arzobispos los dos primeros de Triumpho reymundino Sevilla y los otros dos de Toledo [...]. Dice deste linaje el bachiller Trasmiera en su que vienen del linaje de sant Benito. Son estas sus palabras, refiriendo la victoria que alcanzó el caballero de la casa de Matanza, las palabras que se siguen:

De Palomeques memoria

(linaje de sant Benito)

del rey Alfonso bendito

en toledana victoria.

Solar insignia notoria

de los cuatro toledanos,

Palomas cinco que a manos

al león dan leal gloria.

[Higuera, Familias de Toledo, f. 237]

En efecto, el bachiller Trasmiera había compuesto un Triunfo raimundino, hoy consultable en la Biblioteca Nacional de España. Un poco más adelante continúa Higuera: «Unos mismos principios tiene esta casa de los Palomeques que tuvo la Casa de Austria, sino que esta viene por varón y la de los Palomeques por hembra» (f. 243v). Nada menos, pues, que linaje de 
san Benito y de la casa reinante. No se olvide que otro episodio del primer Quijote sucede con unos frailes benitos, precisamente, caballeros en mulas tan grandes como dromedarios. ¿Nueva hipérbole burlesca de Cervantes en la misma dirección? Es posible.

Ya el sabio Nicolás Antonio clamaba en su Censura de historias fabulosas contra esta nueva superchería del padre Higuera [1742, f. 609], que había falsificado o mixtificado la información en uno de sus legendarios cronicones para mayor gloria de la familia Palomeque, cuyo nombre venía de un suceso fabuloso como que una paloma se hubiera posado encima del hombro de un miembro de la familia. Por supuesto, el grupo de escritores que consideraba a Lope como cabeza en Toledo aceptaba a pie juntillas esta dignificación de un apellido y un colectivo, los mozárabes, que enaltecían la fe de los toledanos.

Así, una de las familias que proponía Higuera como ejemplo de la fe mantenida a lo largo de los siglos de dominación musulmana en la ciudad, resultaba ridiculizada en el nombre de este ventero que, por si fuera poco, tenía como apelativo el «Zurdo», es decir, el siniestro. Además, el dicho ventero era cuadrillero de la Santa Hermandad vieja de Toledo, que tampoco es capaz de actuar convenientemente y que participa en aporreos varios justamente en la venta, donde Palomeque trataba a su criada Maritornes de «puta» sin ambages. Indudablemente Cervantes se burlaba, o podía interpretarse que lo pretendía, de este viejo grupo, entre los cuales se contaban varios capellanes mozárabes de iglesias toledanas, amigos de Lope.

Porque Lope había tomado partido a favor de este grupo de los mozárabes y de los sacerdotes del mismo nombre: es amigo de varios de ellos cuando habita en Toledo, como los maestros José de Valdivielso, Eugenio de Robles, Alonso de Villegas o Francisco de Pisa, y son Lope y su grupo los que suelen colaborar en los epicedios de los libros que estos publican en esos años en Toledo. Pero como todo grupo singular, estos capellanes mozárabes se enfrentaron en la ciudad a los llamados «latinos», los de las otras parroquias que no seguían el rito gótico, según hemos escrito en otro lugar [Madroñal, 2014]. Además, los mozárabes se sentían apoyados por el propio cardenal Sandoval y Rojas, aunque tuvieron también enemigos irreconciliables, como el canónigo doctor Pedro Salazar de Mendoza, acaso el canónigo de Toledo de las páginas el primer Quijote, como también he propuesto.

Hay que recordar que a Lope se le atribuye precisamente la comedia $L a$ paloma de Toledo, en la que se pretende alabar esta familia y en especial a doña Violante y don Alonso Palomeque ${ }^{2}$, pero parece más bien obra de algún otro comediógrafo (en el final de la misma el autor se dice hijo de Toledo), pues hay en ella hay una clara alusión al Fénix, que no parece lógico que el poeta se dedicara a sí mismo:

2. En un impreso suelto se le atribuye a Lope de Vega y se dice que la representó Avendaño, sin datos. Gallica, BNF. Consulta en línea. 


\author{
Heroico Plauto español, \\ Vega ilustre, a cuya frente \\ es corona conveniente \\ los nobles rayos del sol, \\ describe esta heroica hazaña, \\ pues a ti conviene solo; \\ sea coronista Apolo \\ de acciones de un rey de España \\ [Lope, La paloma de Toledo, p. 311].
}

Puede referirse a la comedia de Lope Los Guzmanes del Toral, pues a un Guzmán le suceden los hechos que se narran. Evidentemente, no parece probable que Lope escriba estos versos para referirse a sí mismo. Por su parte, la comedia se sitúa entre 1599 y 1603, según Morley-Bruerton, que así lo indican «si es de Lope» [1968, p. 475-476].

Por si fuera poco, Pero Díaz Palomeque es el protagonista de una anécdota histórica o que el padre Higuera ofrece como tal, cuando se encuentra en el episodio de Lope de Arenas en el castillo de Zurita, que es conquistado por el rey gracias a la intervención de un bufón apodado Dominguejo. El tal Pero Díaz consigue el sobrenombre de «el del bofetón», porque sufre tal agresión o mazazo, según sigue contando el propio Higuera:

\begin{abstract}
Sirvió al rey don Alonso el 8 en el cerco de Zurita, como le sirvió él y los de su linaje cuando don Esteban Illán le recibió en Toledo; y como el rey concertase con Dominguejo, que era truhán de Lope de Arenas, alcalde a la fortaleza de Zurita, que le matase a su amo par que le diese entrada, dijo que daría con una maza en el hombro a un caballero de los más allegados de su casa y que él se daría al tiempo que Lope de Arenas se asomase entre las almenas del castillo y que él se iría corriendo al castillo, y así alcanzaría privanza con su señor y le mataría. Era de grande importancia esta fuerza por estar en las fronteras de Cuenca, y así íbale mucho al rey en ganalla. Salió Pero Díaz Palomeque, gran servidor del rey y valiente capitán y muy diestro en armas; ofreciose de sufrir aquella mazada o puñalada (Gracia Dei dice fue bofetón; más cierto es lo que dice la General) y fue tan poderoso el golpe que cayó el capitán Pero Díaz Palomeque, si ya él no se arrojó en el suelo. Al fin por esta vía se cobró el castillo y se le dio después a la orden de Calatrava [Higuera, Familias de Toledo, ms., f. 244].
\end{abstract}

Curiosamente entre los miembros de la familia de este personaje, Pero Díaz Palomeque, se encuentra, el alcaide don Alonso Quesada, según el rey, que le hace merced el año 1325 en estos términos:

Alonso de Quesada, caballero hijodalgo, mi criado e leal vasallo e servidor, vecino de Baeza, e quanta lealtad en vos fallamos de las fianças que de vos fecimos e de los muchos i buenos i leales servicios que nos habedes fecho e por quanto afán trabajó por nos servir habedes pasado, e por las grandes fazañas que por servicio de Dios i nuestro fecisteis 
assí contra los moros enemigos de nuestra sante fee católica como contra otras personas que fueron contra nuestro servicio de que mucha parte fue en nuestra presencia e cierta sabiduría e por vos dar galardón de esta lealtad e servicios que en vos fallamos siempre porque vos e los de vuestro linaje seades de más valor e hayades premio e mejoría para facer continuar nuestro servicio y quede memoria perpetua para otros que lo supieren e oyeren e tomen dello buen exemplo, etc. [Higuera, Familias de Toledo, ms. ff. $\left.250 \mathrm{y} \mathrm{v}^{\circ}\right]$.

A este Alonso Quesada le sucede Pero Díaz de Quesada, que casó con doña Juana Cárcamo, según se indica en la misma fuente, que creo que no por casualidad comparte apellido con el corregidor toledano Alonso del Cárcamo, en esos años, importante por su relación con Lope y Cervantes, dado que al primero le encarga la composición y publicación de la Justa toledana de 1605 al nacimiento de Felipe IV y La noche toledana y el segundo lo menciona (aunque convenientemente deformado su nombre de pila) en su novela La gitanilla.

No se puede olvidar que los Quesadas, sigue diciendo Higuera en el manuscrito citado, "son por vía de padre finos Palomeques y no sé por qué se permitieron perder el nombre tan ilustre y antiguo de Palomeques por el de Quesada, que no es tan antiguo ni desde tiempos tan antiguos y muchos menos debieran perder las armas de la paloma» [Higuera, Familias de Toledo, ms. f. $252 \mathrm{v}^{\circ}$ ]. Y tampoco que don Quijote dice descender de un Quijada, cuando refiere en la primera parte de la obra:

las aventuras y desafíos que también acabaron en Borgoña los valientes españoles Pedro Barba y Gutierre Quijada (de cuya alcurnia yo desciendo por línea recta de varón) [Cervantes, Don Quijote, 2004, I, 49, p. 507].

El narrador nos informa, sin embargo, en el capítulo primero de que don Quijote:

Quieren decir que tenía el sobrenombre de «Quijada», o «Quesada» [Ibíd, I, 1, p. 28].

Así pues, los Palomeque tenían relación familiar con los Quesada, uno de cuyos miembros, de nombre don Alonso, había servido de forma importante a su rey. Son demasiadas coincidencias como para no tenerlas en cuenta.

\section{LA RELACIÓN DE LOS PALOMEQUE CON LA COMEDIA DE LOPE LAS PACES DE LOS REYES Y JUDÍA DE TOLEDO}

El caso es este Pero Díaz Palomeque es un personaje importante también de Las paces de los reyes y judía de Toledo, de Lope, solo que allí se omite el segundo apellido y se deja al caballero con el poco caballeresco nombre 
de Pero Díaz. Lope cuenta la misma historia que Higuera en este nobiliario del que venimos hablando y trata también del episodio de Lope de Arenas y Dominguejo (Dominguillo en Lope). Porque esta comedia, titulada Las paces de los reyes y judía de Toledo, pero conocida también como La judía de Toledo, la escribe Lope hacia 1610-12 [Morley-Bruerton, 1968, p. 372], (pero tal fecha la retrotrae a finales de 1605 Wilder [1952], cosa que parece muy posible). La obra comienza en el muro de Toledo, desde donde Esteban Illán y el conde don Manrique exhortan a los habitantes de la ciudad para que reconozcan al niño Alfonso como legítimo rey de Castilla. Al alboroto acuden Fernán Ruiz y Lope de Arenas quienes, de acuerdo con el testamento de Sancho el Deseado, recuerdan su compromiso de no entregar Toledo ni Zurita hasta que Alfonso cumpla quince años. Éste aparece entonces en la torre de San Román y Fernán Ruiz le rinde de inmediato el alcázar toledano, pero Lope de Arenas regresa a Zurita dispuesto a mantener la plaza fiel a Fernando de León. En Zurita, Costanza aguarda con el criado Dominguillo la llegada de Lope de Arenas, su esposo, cuando sabe que Alfonso se ha proclamado rey en Toledo. Pasado un tiempo, Alfonso se presenta con su ejército frente a las murallas de Zurita y Dominguillo se brinda a entregarle la fortaleza traicionando a Lope de Arenas y así Alfonso toma Zurita, pero cuando el criado reclama su premio al rey, éste sorprende a todos al concederle una cantidad en pago por el servicio prestado y ordenar seguidamente que le saquen los ojos al traidor como castigo de su crimen.

En el acto segundo han transcurrido varios años desde la toma de Zurita. Alfonso, que ha sabido consolidar con las armas su reino y poner coto a las ambiciones de su tío el rey Fernando de León, vuelve a Toledo después de casarse en Burgos con Leonor, hija de Ricardo, rey de Inglaterra, al que había acompañado en la Cruzada de Tierra Santa. Una tarde, paseando a orillas del Tajo con Garcerán, Alfonso descubre a Raquel bañándose en compañía de su hermana Sibila. Arrebatado por los encantos de Raquel, el rey convierte a la hermosa judía en su amante y dispone su alojamiento en los palacios de Galiana, donde pasa el tiempo distraído de los asuntos del reino. Un día, de vuelta de una de sus ausencias, Alfonso sorprende a Leonor escribiendo una carta en la que expresa sus celos. Tras leer el escrito, Alfonso desmiente las sospechas de su esposa y, después de ignorar una exhibición de tropas dispuestas a servirle, acude a visitar una vez más a Raquel. David, yendo a Galiana para ver a su hija, anticipa que los celos de la reina desencadenarán la muerte trágica de Raquel. Esa misma noche, camino de su cita, una misteriosa voz reconviene a Alfonso y una sombra le impide la entrada en el palacio. El rey atribuye a un hechizo los extraños.

El acto tercero sucede siete años más tarde, Leonor reúne a los nobles de Toledo para pedirles que por el bien del reino actúen contra la judía que tiene fascinado y cautivo de sus encantos al rey. Las palabras de la reina y de su hijo, el infante Enrique, acaban convenciendo a todos los presentes de que Raquel debe morir. Pescando en el río, Raquel saca una calavera y Alfonso un ramo de olivo, lo cual es interpretado por el hortelano Belardo como una 
premonición de la muerte de la judía y de la consiguiente reconciliación de los reyes. Alfonso vuelve a Toledo con Fernán Ruiz, ocasión que los nobles aprovechan para asesinar a Raquel y a su hermana. Al conocer el trágico suceso, Alfonso jura vengar la muerte de su amada y se va a Illescas. Y allí, en la iglesia de la Caridad, un ángel se le aparece para recriminarle sus pecados. $\mathrm{Al}$ arrepentimiento del adúltero sigue la anagnórisis de los esposos en el mismo templo, que da lugar al perdón de Leonor y a la restauración de la armonía conyugal. La comedia concluye con el regreso a Toledo para celebrar las paces de los Reyes.

Los estudiosos han señalado que Lope se basa en la Crónica de España, de Florián de Ocampo (1541), la cual sirve de fuente también para varios romanceros, que cuenta los amores de este con una judía toledana y la marcha a Illescas del monarca, donde un ángel le recrimina su actitud, lo que le hace arrepentirse al rey y volver a Toledo para gobernar junto a la reina. Lope había tratado ya el tema en la Jerusalén (1609) [Acebrón, 2008, pp. 596-598], donde justamente da el nombre de Raquel a la protagonista, ligándolo ya para siempre a la tradición dramática que renovará una y otra vez el tema hasta el siglo XVIII. Ahora bien, puede que no sea la única fuente del dramaturgo, habida cuenta de que también trata el suceso Juan de Mariana en su Historia de España, que necesariamente conocía Lope. Mariana simplemente recuerda de pasada el episodio, al que parece darle credibilidad histórica.

Es muy probable que Lope escribiera la comedia cuando vivía en Toledo (1604-1610) y que, mitómano como era, según recuerda Felipe Pedraza [2001, p. 179], le gustase trasladar su vivencia personal de hombre casado con Juana Guardo, pero que a la vez era amante de Micaela Luján; tal y como le ocurría al rey Alfonso en la comedia. En ella aparecen también Garcerán y Belardo, este último a veces hace el papel de gracioso y representa al mismo Lope e incluso canta su famosísimo romance:

Hortelano era Belardo de las huertas de Valencia, que los trabajos obligan a lo que el hombre no piensa.

Es hombre leído y que ha ido a la escuela, y es evidente que alude al propio Lope, cuando le dice a su amigo Fileno:

Con los perros desta huerta [del Rey]

traigo pendencia encubierta

y para mí declarada

y responde el otro: «¿qué hay a quien tu vida pese», para contestar Belardo:

Es la envida mal nacida. [...]

Todos me muerden en vano;

que al fin de tantos destierros 
ellos se quedan por perros y yo me quedo hortelano. [Lope, Las paces de los reyes, 2008, p. 645].

No sabemos si esa envidia puede eludir el nombre de Cervantes, pero es posible. Belardo-Lope se queja luego de las necedades del mundo y del trocar de los nombres, cosa que parece convenirle a él especialmente. Acaso los nombres de Belardo y Garcerán pueden ser un guiño también de la comedia La famosa toledana (1591), del jurado de la ciudad Juan de Quirós, pues allí aparecen igualmente.

La reina Leonor alaba a los nobles Blasco de Guzmán, Beltrán de Rojas y al ilustre Illán de Toledo (hijo de don Esteban), además de a Garcerán Manrique, apellidos todos relacionados con el Toledo histórico y algunos con los toledanos del momento. No se olvide que don Francisco de Rojas y Guzmán, segundo conde de Mora, era protector del poeta Baltasar de Medinilla y buen amigo de Lope, aparte de ser familia del arzobispo don Bernardo de Sandoval y Rojas. Por otra parte, se alaba la valentía de un soldado de Toledo: «Pero Díaz», que se ofrece a ser herido y aun muerto por conquistar el castillo de Zurita que no le rinde al rey Alfonso, que exclama: «De dónde pudieras ser / mejor un hombre sin miedo» [Lope, Las paces de los reyes, 2008, p. 626.] Y le dice que le tiene envidia y que con su sangre le dibuja en su escudo el blasón de la nobleza:

Estas diez bandas harán y por armas quedaron a los Díez toledanos [Lope, Las paces de los reyes, 2008, p. 628].

Posible intención adulatoria de Lope en esta comedia a una familia toledana, los Palomeque, que no era sino una de las muchas familias nobles que por entonces existían y podían encargarle comedias, justo como los Guzmán, Manrique y otros. $\mathrm{O}$ como las menos nobles, pero no menos pudientes, como la familia Franco, también relacionada con el fénix en la comedia El Hamete de Toledo, ya estudiada [Madroñal. 2013]. El toledano queda castellano de Zurita. Por otra parte, el arrepentimiento del rey Alfonso VIII (1155-1214) tiene lugar en la villa de Illescas, donde se le aparece un ángel y donde el rey pregunta a Garcerán:

¿No hay una virgen aquí

de gran devoción y fama?

A lo que responde el noble: «De la Caridad se llama». Indudablemente la comedia alude a la villa y a su virgen, pues Illán incide sobre la virgen citada y su ermita:

¿Sola una lámpara tiene casa de tantos milagros. 
Beltrán le responde:

Gastan todas las limosnas

que dan a este templo santo

en sustentar pobres viudas,

vestir pobres y curarlos.

[Lope, Las paces de los reyes, 2008, p. 685].

...y se cuenta que Ilefonso, / de Toledo pastor santo, / la tenía en su oratorio»' [Lope, Las paces de los reyes, 2008, p. 686], en alusión al santo toledano por excelencia, san Ildefonso. En ese momento, el rey y la reina rezan a la Virgen por separado en un contrapunto muy efectista y piden que les reconcilie y así acaba la comedia.

En efecto, la iglesia de Illescas conservaba una capilla llamada del Ángel donde según la tradición se arrepintió Alfonso el de las Navas de su trato ilícito con la judía de Toledo y un cuadro y una lápida, ambos del siglo XVII allí lo conmemoraban, aunque el suceso no es histórico, según sabemos hoy [Aguilar: c. 1920, p. 18 nota.]. La misma fuente señala que existía una Hospital de Nuestra Señora de la Caridad, en el que había también un monasterio y la imagen de la Virgen de la Caridad; pero fue en 4 de junio de 1600 fue cuando se terminó de «levantar un templo más suntuoso a la Virgen de la Caridad» [Aguilar: c. 1920, p. 20]. En 1603 se contrató que el Greco pintara unos cuadros para dicho Hospital [San Román: 1982, p.175], uno de ellos justamente de la Virgen de la Caridad. Se ha puesto en relación suficientemente esta comedia con el largo pasaje que dedica Lope en el libro 19 de la Jerusalén conquistada a los amores de Alfonso y Raquel [2003, pp. 796-808], donde por primera vez aparece el nombre de la hermosa judía. Si, como se nos ha dicho, la obra estaba terminada en 1605, aunque se publicara en 1609, puede dar una pista sobre la fecha de composición de la comedia, que según mi opinión no puede estar muy lejos del primero de los años ${ }^{3}$.

Lope se pone del lado de los que echan la culpa al rey Alfonso de la pérdida de la batalla de Alarcos, exculpando así a su gentilhombre Diego López de Haro. Dicha pérdida sería un castigo divino por le divertimento con la judía, olvidando sus ocupaciones familiares y militares. La reacción del monarca le valió la victoria en Las Navas de Tolosa. Por supuesto, la comedia de Lope es interesada: trata de posicionarse en favor de la importancia de Illescas también, en un momento en que se encarga al Greco un buen número de pinturas para adornar el Hospital y la iglesia de la villa: juntas pintura y poesía, nuevamente el Greco con los mejores literatos toledanos, como ocurre con su amigo Valdivielso y su Vida de san José (prácticamente de las mismas fechas: 1605). Como él,

3. He investigado en el archivo de la fundación de la Virgen de la Caridad (Funcave), de la villa de Illescas, por si se conserva el documento del encargo a Lope esta obra, pero no lo he encontrado. Podría ser que las pinturas del Greco y la comedia fueran un encargo coincidente en el tiempo para dar más auge al hospital y a la villa de Illescas a principios del siglo XVII y promocionarla como centro de peregrinación. 
Lope participa también con el más importante pintor toledano en la exaltación de una villa que estaba intentando promocionarse a principios del XVII (especialmente por su famoso Hospital y su devoción a la Virgen de la Caridad) y para ello encarga por lo menos dos comedias al más importante poeta y a la vez varios cuadros al pintor más señalado de aquel tiempo, casualmente ambos (Lope y el Greco), residentes en Toledo. De paso, alude Lope a las familias nobles más importantes de Toledo, como los Illán y los Palomeque, al contrario de Cervantes que parecía burlarse de tan gran linaje mozárabe con el nombre del ventero socarrón de la primera parte del Quijote.

Así pues, este Juan Palomeque podía entenderse como un sinónimo voluntario, es decir, un nombre en la ficción que se podía interpretar como intencionadamente puesto para relacionarlo con otro en la realidad que causara molestia a Lope de Vega y al grupo de intelectuales toledanos de los que se rodeaba en esa etapa de su vida, cuando la publicación del primer Quijote. No quedaría ese ataque sin respuesta, como sabemos, pero ese es otro capítulo no menos apasionante de nuestra historia literaria.

\section{BIBLIOGRAFÍA CITADA}

Acebrón, Julián (2008). «Introducción a Lope de Vega: Las paces de los Reyes y judía de Toledo», en Comedias de Lope de Vega. Parte VII, Enrico di Pastena (coord.). Lérida: Milenio-Universitat Autònoma de Barcelona, 3 vols, II, pp. 593-703.

Aguilar, Alberto de (s. a. [c. 1920]). Illescas. Notas histórico artísticas. Madrid: Hauser y Menet.

Alonso Hernández, José Luis y Huerta Calvo, Javier (2000). Historia de mil y un Juanes. Salamanca: Universidad de Salamanca.

Antonio, Nicolás (1742). Censura de historias fabulosas. Valencia: Antonio Bordázar de Artazu.

Bernaldo de Quirós Mateo, José Antonio (2007). «Otra posible interpretación de los «sinónomos voluntarios» de Avellaneda», Lemir. 11, pp. 117-120.

Camacho Morfín, Lilián (2002). Las armas de don Quijote (sinónimos voluntarios). México: Taller Abierto.

Caro Baroja, Julio (1996). Las falsificaciones de la Historia en relación con la de España. Barcelona: Círculo de Lectores.

Cervantes, Miguel (1922). Viaje del Parnaso, Rodolfo Schevill y Adolfo Bonilla (ed.). Madrid: Gráficas Reunidas.

Cervantes, Miguel de (20014). Don Quijote de la Mancha. Francisco Rico (ed.). Madrid: Círculo de Lectores-Galaxia Gutenberg.

Fernández de Avellaneda, Alonso (2014). Segunda parte de don Quijote de la Mancha. Luis Gómez Canseco (ed.). Madrid: Real Academia Española.

García-Arenal, Mercedes (2010). «Miguel de Luna y los moriscos de Toledo: No hay en España mejor moro», Chronica Nova. 36, pp. 253-262.

García Arenal, Mercedes y Fernando Rodríguez Mediano (2009). «Jerónimo Román de la Higuera and the lead books of Sacromonte», en The conversos and moriscos in late medieval Spain and beyond: departures and change. Kevin Ingram (ed.). Leiden: Brill, I, pp. 243-268. 
Godoy Alcántara, José (1868). Historia crítica de los falsos cronicones. Madrid: Rivadeneira.

Higuera, Jerónimo Román de la (1602). Discurso sobre si san Tirso, mártir, fue español y natural de Toledo con ocasión de haber la ciudad establecido cofradía a este santo. Manuscrito autógrafo en la Biblioteca Rodríguez Moñino, signat. 6683. Biblioteca de la Real Academia Española.

Higuera, Jerónimo Román de la (s. f.). Familias de Toledo, ms. s. XVII. Biblioteca de la Real Academia de la Historia, ms 9/229.

Higuera, Jerónimo Román de la (c. 1605). Historia de la Iglesia en Toledo, I-IX. Ms. s. XVII. Biblioteca Nacional de España ms 1285-93.

Horozco, Sebastián de (1994). Libro de los proverbios glosados. Jack Weiner (ed.). Kassel: Reichenberger.

Hurtado de Toledo, Luis (1963). Memorial de algunas cosas notables que tiene la imperial ciudad de Toledo. Carmelo Viñas y Ramón Paz (ed.). Madrid: CSIC.

Madroñal, Abraham (en prensa 2016a). «A propósito de El niño inocente de La Guardia, de Lope de Vega», Rilce.

Madroñal, Abraham (en prensa 2016b). «Jerónimo Román de la Higuera y su influencia en la literatura de su tiempo».

Madroñal, Abraham (2010). «De nuevo sobre «Gante y Luna» (I, 51). ¿Otra errata en el primer Quijote?», en Cervantes: Bulletin of the Cervantes Society of America. 30/1, págs. 16-29.

Madroñal, Abraham (2012). «Entre Cervantes y Lope: Toledo, hacia 1604», eHumanista. I, pp. 300-332.

Madroñal, Abraham (2013). «Sobre la fecha, fuentes y otros aspectos de El Hamete de Toledo, de Lope de Vega», Anuario de Lope de Vega. 19, pp. 32-66.

Madroñal, Abraham (2014). «San Tirso de Toledo, tragedia perdida de Lope de Vega», Hipogrifo. 2/1, pp. 23-54.

Martín Gamero, Antonio (1869). Recuerdos de Toledo sacados de las obras de Miguel de Cervantes Saavedra. Toledo: Imprenta de Fando e hijo.

Martínez de la Escalera, José (1991a). «Jerónimo de la Higuera S. J.: falsos cronicones, historia de Toledo, culto de san Tirso», en Tolède et l'expansion urbaine en Espagne (1450-1650). Madrid: Casa de Velázquez, pp. 69-97.

Martínez de la Escalera, José (1991b). «La circunstancia toledana de una tragedia de Lope y el nombre Tirso», Revista de Literatura. 53, pp. 631-639.

Martínez Gil, Fernando (2000). «Religión e identidad urbana el arzobispado de Toledo (siglos XVI-XVIII), en Religiosidad popular y modelos de identidad en España y América. J. Carlos Vizuete Mendoza y Palma Martínez-Burgos García (coord.) Cuenca: Eds. Universidad de Castilla-La Mancha, pp. 40-41.

Martínez Gil, Fernando (2007). La invención de Toledo. Ciudad Real: Almud.

Morley, G. y Bruerton, C. (1968). Cronología de las comedias de Lope de Vega. Madrid: Gredos.

Olavide, Ignacio (1903). «La Inquisición, la Compañía de Jesús y el P. Jerónimo Román de la Higuera», Boletín de la Real Academia de la Historia. 42, pp. 107-119.

Pedraza, Felipe (2001). «Los judíos en el teatro del siglo XVII: la comedia y el entremés», en Judíos en la literatura española. Iacob M. Hassán y Ricardo Izquierdo Benito (coord.) Cuenca: Ediciones de la Universidad de Castilla-La Mancha, pp. 153-211.

Pérez López, José Luis (2002). «Lope, Medinilla, Cervantes y Avellaneda», Criticón. 86, pp. 41-71.

Relación de fiestas que hizo la ciudad de Toledo por el nacimiento del príncipe Felipe (1605). Madrid: Luis Sánchez.

Rodríguez Marín, Francisco (ed.) (1948). El Quijote, de Miguel de Cervantes. Madrid. 
Rosenblat, Ángel (2014). La lengua del Quijote, Rafael Cano (presentación). Sevilla: Athenaica.

San Román, Francisco de Borja (1935). Lope de Vega, los cómicos toledanos y el poeta sastre. Madrid: Impr. Góngora.

San Román, Francisco de Borja (1982). El Greco en Toledo. Toledo: Zocodover.

Schevill, Rodolfo y Adolfo Bonilla (ed.) (1922). Viaje del Parnaso, de Miguel de Cervantes. Madrid: Gráficas Reunidas.

Suárez Figaredo, Enrique (2006). Los 'sinónomos voluntarios': un reproche sin réplica posible», Parnaseo. [http://parnaseo.uv.es/lemir/Revista/Revista10/SuarezFigaredo2/ SinonimosVoluntarios.htm]

Suárez Figaredo, Enrique (2008). «¿“Ofender a mil’ o ‘a mí'?, una errata plausible», Lemir. 12, pp. 9-18.

Vega, Lope de (2009). El santo niño de La Guardia, en Comedias, Fernando Baños (ed.) Lleida: Milenio, vol. VIII.

Vega, Lope de (2008). Las paces de los Reyes y judía de Toledo, ed. Julián Acebrón, en Comedias de Lope de Vega. Parte VII. Enrico di Pastena (coord.). Lérida: MilenioUniversitat Autònoma de Barcelona, 3 vols, II, pp. 593-703.

Vega, Lope de (atribuida) (1966). La paloma de Toledo, en Obras de Lope de Vega. Madrid: Biblioteca de Autores Españoles, t. XXII.

Wardropper, Bruce W. (1984). «Don Quijote: ¿ficción o historia?», en El Quijote de Cervantes. G. Haley (ed.) Madrid: Taurus, pp. 237-252.

Wilder, Thorton (1952). "New Aids Toward Dating the Early Plays of Lope de Vega", en Varia variorum. Festgabe für Karl Reinhardt. Münster-Koln: Böhlau Verlag, pp. 194-200.

Recibido: 2 de mayo de 2016

Aceptado: 16 de mayo de 2016 